\title{
Informações Financeiras Ambientais: Diferença entre o Nível de Disclosure entre Empresas Brasileiras
}

\begin{abstract}
Resumo
As questões relativas ao meio ambiente e à sustentabilidade têm motivado interesses da comunidade acadêmica e das organizações. O modelo de sociedade atual é permeado pela produção e consumo excessivos, o que vem agravando a relação do homem com a natureza. É um fato que a sociedade, para sua subsistência, necessita da fabricação de produtos e execução de serviços, porém, sabe-se também que fabricar produtos e prover serviços impactam o meio ambiente. O impacto é diferenciado conforme a atividade que é desenvolvida. No Brasil, a Lei no ${ }^{\circ} 10.165 / 2000$ dispõe sobre a Política Nacional do Meio Ambiente e classifica as empresas segundo o impacto ambiental que causam. Esta pesquisa analisou o disclosure voluntário das informações financeiras ambientais em empresas brasileiras, classificadas em setores com diferentes impactos ambientais. Para tanto, foi investigada as Demonstrações Financeiras Padronizadas das empresas que compõem o índice IBrX-50, carteira de maio a agosto de 2014, nos anos de 2011, 2012 e 2013. A métrica classificou as informações financeiras ambientais, distribuindo os dados em 7 categorias e 30 subcategorias. A categoria mais evidenciada é a de investimentos ambientais, com $58 \%$ das informações divulgadas. O maior valor monetário apresentado foi na categoria de passivos e contingências ambientais, com $\mathrm{R} \$ 259,84$ bilhões. Os resultados demonstram que há diferença no disclosure de informações financeiras ambientais se comparados à quantidade de sentenças divulgadas com o número de subcategorias evidenciadas. $\mathrm{O}$ teste não paramétrico e a análise de conteúdo mostraram que, nos anos analisados, as empresas com alto impacto ambiental divulgam mais informações financeiras ambientais.
\end{abstract}

Palavras-chave: Informações financeiras ambientais. Disclosure. Empresas brasileiras.

\author{
Janaina da Silva Ferreira \\ Mestranda em Ciências Contábeis pela \\ Universidade Federal de Santa Catarina \\ (UFSC). Contato: Universidade Federal de \\ Santa Catarina, Campus Universitário Reitor \\ João David Ferreira Lima. Departamento \\ de Ciências Contábeis. Trindade. \\ Florianópolis-SC. CEP: 88.040-900. \\ E-mail: janix_17@msn.com
}

\section{Suliani Rover}

Doutora em Controladoria e Contabilidade pela Universidade de São Paulo (USP) e Professora da Universidade Federal de Santa Catarina (UFSC). Contato: Universidade Federal de Santa Catariana, Campus Universitário Reitor João David Ferreira Lima. Departamento de Ciências Contábeis. Trindade. Florianópolis-SC, CEP: 88040-900. E-mail: suliani.rover@ufsc.br

\section{Denize Demarche \\ Minatti Ferreira}

Doutora em Engenharia e Gestão do Conhecimento pela Universidade Federal de Santa Catariana (UFSC) e Professora da Universidade Federal de Santa Catarina (UFSC). Contato: Universidade Federal de Santa Catariana, Campus Universitário Reitor João David Ferreira Lima. Departamento de Ciências Contábeis. Trindade. Florianópolis-SC, CEP: 88040-900. E-mail: dminatti@terra.com.br

\section{José Alonso Borba}

Doutor em Controladoria e Contabilidade pela Universidade de São Paulo (USP) e Coordenador do PPGC do CSE da Universidade Federal de Santa Catarina (UFSC). Contato: Universidade Federal de Santa Catariana, Campus Universitário Reitor João David Ferreira Lima. Departamento de Ciências Contábeis. Trindade. Florianópolis-SC, CEP: 88040-900. E-mail: jalonso@cse.ufsc.br 


\section{Introdução}

A sociedade, para sua subsistência, necessita da fabricação de produtos e da execução de serviços, porém sabe-se também que fabricar produtos e prover serviços impactam o meio ambiente. $\mathrm{O}$ nível desse impacto é diferenciado conforme a atividade desenvolvida. No Brasil, a Lei no ${ }^{\circ} 10.165 / 2000$ - dispõe sobre a Política Nacional do Meio Ambiente e classifica as empresas em pequeno, médio e alto impacto ambiental.

Nota-se que a sociedade vem exigindo posicionamento das organizações e uma forma de atuar mais responsável com relação às atividades que desenvolvem, visto que é inevitável a utilização dos recursos do meio ambiente e, desta forma, é fundamental o seu uso consciente. Para que a organização tenha boa reputação no aspecto social e ambiental, é importante que conduza as ações com transparência e confiabilidade. Logo, o que se percebe é que as questões relacionadas ao meio ambiente e à sustentabilidade nas diferentes áreas, bem como na contabilidade socioambiental, têm motivado interesses não só da comunidade acadêmica, mas também das empresas (Gray, 2002; Deegan, 2002; Parker, 2011).

Outra exigência diz respeito à crescente demanda pela melhoria da evidenciação dos fatos que afetam não só o meio ambiente, mas também as questões financeiras e econômicas das empresas. Vários países já desenvolveram, desde a década de 1970, um processo de conscientização, pois perceberam a necessidade de controlar processos de fabricação de produtos, bem como emissões de resíduos. Porém, Rover, Murcia, Borba \& Vicente (2008) esclarecem que, no Brasil, não há obrigatoriedade da evidenciação da informação ambiental, mas algumas organizações buscam apresentar diretrizes sobre o disclosure ambiental para as empresas.

Mesmo não havendo obrigatoriedade, há normas que tentam padronizar a informação ambiental para auxiliar o entendimento. Algumas empresas divulgam separadamente tais informações em relatórios, entretanto, o documento formal obrigatório e utilizado por todas as empresas que estão listadas na Comissão de Valores Mobiliários (CVM) são as Demonstrações Financeiras Padronizadas (DFPs). Neste relatório, as companhias de capital aberto divulgam informações econômicas e financeiras e podem apresentar informações adicionais diversas, no qual mencionam voluntariamente informações ambientais.

Portanto, por não ser uma obrigatoriedade, cada empresa opta por divulgar voluntariamente as informações ambientais em diferentes relatórios, criados ao longo dos anos por organizações preocupadas com as questões ambientais. Essa publicidade normalmente está relacionada com os pontos da gestão que a empresa queira e decida que sejam importantes, e o faz de forma discricionária.

A partir da demanda pela melhoria da divulgação dos fatos que afetam não só o meio ambiente, mas também as questões financeiras e econômicas das organizações, este estudo teve como objetivo analisar o disclosure voluntário das informações financeiras ambientais em empresas brasileiras classificadas em setores com diferentes impactos ambientais.

\section{Revisão de Literatura}

\subsection{Disclosure ambiental}

As organizações têm sido pressionadas a se posicionarem em relação às suas atividades e às questões ambientais. Em resposta à exigência por parte dos interessados, percebe-se que o disclosure de informações financeiras ambientais por parte das organizações tem se tornado uma prática crescente e voluntária.

O disclosure ambiental integra as etapas do ciclo contábil proposto por Szuster, Szuster, Szuster e Szuster (2009): a captação; o reconhecimento; o processo de acumulação; a sumarização; e a evidenciação. A captação obtém informações sobre as transações realizadas pela entidade; o reconhecimento entende a necessidade, ou não, de responder quando, como e por quanto reconhecer um ato ou fato contábil; o processo de acumulação é a estruturação do banco de dados com base nos registros efetuados; a sumarização consiste em um resumo dos dados organizados para transformar em informação útil aos usuários da contabilidade; e, por fim, o disclosure, que torna público o conjunto dessas informações. 
Na década de 1970, houve uma profusão de pesquisas nesta temática. Belkaoui (1976) realizou um estudo no qual pesquisou relatórios de 50 empresas americanas e o impacto da evidenciação da poluição ambiental no preço das ações das empresas na bolsa de valores. Na década seguinte, nos anos 80, outros autores focaram suas publicações na mesma linha: Igram e Frazier(1980); Wiseman (1982) e Freedman e Jaggi (1986). E, desde a década de 1990, as pesquisas estão cada vez mais frequentes, destacando-se: Harte e Owen, 1991; Epstein e Freedman, 1994; Gray, Walters, Bebbington e Thompson, 1995 e Milne e Adler, 1998.

Nos anos seguintes, pela importância cada vez maior que se tem dado às questões do meio ambiente, diversos autores continuaram direcionando seus estudos para a evidenciação ambiental e assim houve uma proliferação ainda maior de pesquisas relacionadas ao tema (Iman, 2000; Al-Khater \& Naser, 2003; Villiers \& Staden, 2006; Cho, Roberts \& Patten, 2010; Cho, Guidry, Hageman \& Patten, 2012; Andrikopoulos \& Kriklani, 2013; Burgwal \& Vieira, 2014; Ferreira, Borba \& Rosa, 2014). No Brasil, alguns autores também centraram seus estudos na mesma temática (Rover et al. 2008; Ribeiro, Nascimento \& Bellen, 2009; Freitas \& Oleiro, 2011; Santos, Vargas, Almeida \& Lavarda, 2012; Fernandes, 2013; Abreu, Fernandes, Assis \& Silva Filho, 2014).

A preocupação pelas questões relativas ao meio ambiente tem estimulado as organizações a evidenciarem informações. Mesmo que não seja obrigatória, a divulgação de tais dados tem sido apontada como uma estratégia e uma vantagem competitiva. Assim, as pesquisas citadas se preocuparam em identificar quais variáveis influenciam positivamente ou negativamente, no que tange à evidenciação de informações ambientais. Além disso, buscaram verificar que tipos de informações ambientais são mais citadas e se influencia o nível de disclosure a participar de algum índice da área ambiental.

\subsection{Diretrizes para Divulgação Ambiental no Brasil}

No Brasil, não é obrigatória a evidenciação de informações ambientais. As leis n. ${ }^{\circ}$ 6.404/1976, 11.638/2007 e 11.941/2009 não discutiram de forma clara como as disposições sobre as questões ambientadas devem ser alocadas no Relatório de Administração, Notas Explicativas e quadros suplementares. A Comissão de Valores Mobiliários (CVM) propõe, no Parecer de Orientação n. ${ }^{\circ} 15 / 1987$, que conste no Relatório da Administração informações sobre os investimentos que a empresa efetuou na área ambiental (Abreu et al., 2008). Outra recomendação é a Norma e Procedimento de Auditoria n. ${ }^{\circ} 11$, do Instituto dos Auditores Independentes do Brasil (IBRACON, 1996) - revogada pela Diretoria Nacional em 24/5/2011, e a Resolução n. ${ }^{\circ}$ 1.003/2004 do Conselho Federal de Contabilidade (CFC, 2004), que aprova a Norma Brasileira de Contabilidade Técnica n. ${ }^{\circ} 15$.

A Instrução CVM n. ${ }^{\circ} 331 / 2000$ traz um item que remete às informações qualitativas do formulário de Informações Anuais - (IAN). Focado na contabilidade ambiental, Vellani (2011) sintetiza o relatório IAN como um documento enviado pelas companhias com ações na BM\&FBOVESPA à CVM para evidenciar, por meio do item 15, a relação da empresa com os ecossistemas. Atualmente, com a revogação de tal instrução pela 480/2009, o formulário IAN, utilizado na divulgação de informações não contábeis, foi substituído pelo Formulário de Referência (FR), que se diferencia pelo nível de exigência.

O Instituto Brasileiro de Análise Social e Econômica (Ibase) elaborou um modelo de Balanço Social que sugere a divulgação dos gastos efetuados com o meio ambiente para uso das empresas cuja subdivisão deve ser: investimentos em meio ambiente relacionados com a operação da empresa e investimentos em meio ambiente em programas/projetos externos. Segundo Abreu et al. (2008, p. 6), "embora esse modelo do Ibase já seja um avanço na evidenciação de informações ambientais no balanço social, ele merece maior desdobramento e sofisticação, de modo a gerar informação significativamente útil para os usuários".

Ainda se pode mencionar a ITG 2004 - Interação da Entidade com o Meio Ambiente (CFC, 2013), que esteve em audiência pública até 10 de setembro de 2013 com o objetivo de "definir os conceitos e os critérios para a divulgação de informações quantitativas e qualitativas de natureza ambiental contidas nas demonstrações contábeis e que reflitam as interações da entidade com o meio ambiente”. 
A obrigatoriedade da evidenciação de informações ambientais está sendo buscada, por exemplo, por meio do projeto de Lei do Senado no 289, de 2012, que está tramitando no Congresso Nacional. Tal lei pode tornar a publicação do relatório de sustentabilidade obrigatória para as Sociedades Anônimas por Ações (S.A).

A busca pela evidenciação também ocorre por meio do relato integrado que, conforme o Conselho Internacional para Relato Integrado (IIRC, 2014), é um "documento conciso sobre como a estratégia, a governança, o desempenho e as perspectivas de uma organização, no contexto de seu ambiente externo, levam à geração de valor em curto, médio e longo prazo".

Apesar da falta de normalização legal, Ribeiro (2006, p. 141) afirma que "há uma quantidade razoável de orientações quanto à forma e conteúdo da divulgação das informações de natureza ambiental e de empresas que já tomam a iniciativa de evidenciar sua conduta frente a essas questões, infelizmente, a maioria na forma dissertativa e sem quantificações".

\section{Metodologia}

Para o estudo, foram selecionadas as empresas listadas no índice IBrX-50 referentes à carteira de maio a agosto de 2014 (anos de 2011, 2012 e 2013), que mede o retorno total de uma carteira teórica composta por 50 ações selecionadas entre as mais negociadas na BM\&FBOVESPA em termos de liquidez, ponderadas na carteira pelo valor de mercado das ações disponíveis à negociação. Para pertencer ao índice IBrX-50, as empresas devem estar entre os 50 papéis mais líquidos, desde que atendidos os seguintes requisitos: estar entre as 50 ações com maior índice de negociabilidade nos últimos doze meses e ter sido negociada em pelo menos $80 \%$ dos pregões ocorridos no mesmo período (BM\&FBOVESPA, 2014).

Na pesquisa optou-se por uma amostra que englobasse empresas com os três níveis de poluição (pequeno, médio e alto), conforme classificação da Lei n. ${ }^{\circ} 10.165$, de 27 de dezembro de 2000. A amostra final é composta por 46 empresas, pois três delas (Bradesco, Petrobras e Vale) participam do índice com ações preferenciais e ordinárias. A BB Seguridade foi constituída em dezembro de 2012 e abriu seu capital em abril de 2013, e, por não possuir os documentos da pesquisa nos três anos do estudo e não poder apresentar a evolução no período, foi retirada da amostra. A Tabela 1 apresenta a classificação dos setores que compõem a amostra da pesquisa e o potencial poluidor.

Tabela 1

Classificação das atividades potencialmente poluidoras e utilizadoras de recursos ambientais

\begin{tabular}{|c|c|c|c|}
\hline Potencial Poluidor & Setor & Total por setor & Total de empresas \\
\hline \multirow{4}{*}{ Alto } & Bens Industriais & 1 & \multirow{4}{*}{10} \\
\hline & Consumo Não Cíclico & 1 & \\
\hline & Materiais Básicos & 7 & \\
\hline & Petróleo, gás e biocombustíveis & 1 & \\
\hline \multirow{3}{*}{ Médio } & Consumo Não Cíclico & 5 & \multirow{3}{*}{8} \\
\hline & Consumo Cíclico & 1 & \\
\hline & Utilidade Pública & 2 & \\
\hline Baixo & Construção e Transporte & 5 & 5 \\
\hline \multirow{4}{*}{ Não poluidor } & Consumo Não Cíclico & 1 & \multirow{4}{*}{23} \\
\hline & Consumo Cíclico & 6 & \\
\hline & Financeiro e outros & 13 & \\
\hline & Telecomunicações & 3 & \\
\hline Total & & 46 & 46 \\
\hline
\end{tabular}

Fonte: elaborada pelos autores 
A escolha das DFPs para a realização da pesquisa ocorreu, pois no caso específico das Sociedades Anônimas por Ações (S.A), a CVM regula e impõe a divulgação das DFP através da Instrução CVM 331 (4/4/2000), alterada pelas Instruções CVM 431/2006 e 469/2008 e Revogada pela Instrução CVM 480/2009 contida dos seguintes documentos, entre outros, demonstrações financeiras e consolidadas dos últimos três exercícios sociais e ajustadas/adaptadas ao ambiente contábil brasileiro, acompanhadas de Relatórios da Administração, Parecer de Auditores Independentes, formulário de DFP e Notas Explicativas. Para padronizar os dados, elaborou-se uma métrica com os principais temas encontrados em estudos anteriores de informações financeiras ambientais (Tabela 2).

Tabela 2

\section{Resumo de conceitos de Informações Financeiras Ambientais}

\begin{tabular}{ll}
\hline $\begin{array}{l}\text { Investimentos } \\
\text { ambientais }\end{array}$ & $\begin{array}{l}\text { São os recursos aplicados na área ambiental que protejam, reduzam ou eliminem um risco } \\
\text { potencial à natureza, seja de cunho educacional ou operacional. }\end{array}$ \\
\hline $\begin{array}{l}\text { Ativos ambientais } \\
\text { tangíveis }\end{array}$ & $\begin{array}{l}\text { São os bens e direitos adquiridos que possuam o intento de controlar, preservar e recuperar } \\
\text { o meio ambiente com a prerrogativa de que possam gerar benefícios. }\end{array}$ \\
\hline $\begin{array}{l}\text { Ativos ambientais } \\
\text { intangíveis }\end{array}$ & São bens e direitos incorpóreos de cunho ambiental. \\
\hline Ativos contingentes & Trata-se de uma incerteza da realização de um ganho ambiental e não deve ser contabilizado. \\
\hline $\begin{array}{l}\text { Passivos e contingências } \\
\text { ambientais }\end{array}$ & $\begin{array}{l}\text { São as obrigações decorrentes de danos provocados à natureza provenientes das atividades } \\
\text { da empresa, que resultem em entrega de ativos, prestação de serviço ou renúncia de } \\
\text { benefícios econômicos futuros. }\end{array}$ \\
\hline $\begin{array}{l}\text { Receitas ambientais } \\
\text { Custos e/ou despesas } \\
\text { ambientais }\end{array}$ & $\begin{array}{l}\text { São os recursos provenientes da venda de subprodutos, produtos ecológicos, resíduos e } \\
\text { materiais reciclados, bem como de serviços de gestão ambiental. }\end{array}$ \\
\hline $\begin{array}{l}\text { Fonte: elaborada pelos autores } \\
\text { receita; enquanto as despesas são os gastos não relacionados à fabricação dos produtos. }\end{array}$ &
\end{tabular}

A evidenciação foi categorizada, conforme Rover et al. (2008), em Qualitativa (Q), Quantitativa Não Monetária (QNM) e Quantitativa Monetária (QM). A informação Qualitativa é mencionada em termos descritivos; a Quantitativa Não Monetária é relatada em números de natureza não financeira; e Quantitativa Monetária, em números de natureza financeira. Ressalta-se que foram considerados os valores monetários apresentados no conjunto das DFPs consolidadas. Para a métrica, foram elaboradas as categorias: investimentos ambientais, com cinco subcategorias; ativos ambientais tangíveis, com três subcategorias; ativos ambientais intangíveis, com duas subcategorias; ativo contingente; passivos e contingências ambientais, com quatro subcategorias; receitas ambientais, com quatro subcategorias; e custos e/ou despesas ambientais, com doze subcategorias, totalizando sete categorias e trinta subcategorias (Tabela 3). 
Tabela 3

\section{Métrica de informações financeiras ambientais}

\begin{tabular}{|c|c|}
\hline Categorias & Informações Financeiras Ambientais \\
\hline $\begin{array}{l}\text { Investimentos } \\
\text { Ambientais }\end{array}$ & $\begin{array}{l}\text { Manutenção/modificação nos processos operacionais para a melhoria do meio ambiente; } \\
\text { recuperação de ambientes degradados; educação ambiental para empregados, } \\
\text { terceirizados, autônomos e administradores da entidade; educação ambiental para a } \\
\text { comunidade; programas e projetos ambientais. }\end{array}$ \\
\hline $\begin{array}{l}\text { Ativos Ambientais } \\
\text { Tangíveis }\end{array}$ & $\begin{array}{l}\text { Máquinas/equipamentos/instalações para redução de resíduos poluentes; máquinas/ } \\
\text { equipamentos/instalações para fabricação de subprodutos; estoque de insumos e peças e } \\
\text { acessórios utilizados no processo de redução ou eliminação dos níveis de poluição. }\end{array}$ \\
\hline $\begin{array}{l}\text { Ativos Ambientais } \\
\text { Intangíveis }\end{array}$ & Marca, licença e/ou patente; desenvolvimento de produtos e tecnologias na área ambiental. \\
\hline Ativo Contingente & Ativo contingente \\
\hline Passivos e Contingências & Passivo e provisão provável; provisão possível; provisão remota; provisão sem probabilidade. \\
\hline Receitas Ambientais & $\begin{array}{l}\text { Venda de material reciclável; venda de créditos de carbono; venda de produtos/subprodutos } \\
\text { de linha sustentável; venda de resíduos. }\end{array}$ \\
\hline $\begin{array}{l}\text { Custos e/ou Despesas } \\
\text { Ambientais }\end{array}$ & $\begin{array}{l}\text { Manutenção/ modificação nos processos operacionais para a melhoria do meio } \\
\text { ambiente; recuperação de ambientes degradados; educação ambiental para empregados, } \\
\text { terceirizados, autônomos e administradores da entidade; educação ambiental para } \\
\text { a comunidade; programas e projetos ambientais; licenciamentos e/ou certificações } \\
\text { ambientais; consultoria para elaboração de estudo de impacto ambiental (ElA) e relatório } \\
\text { de impacto ambiental (Rima); gastos com pesquisa para desenvolvimento de produtos e } \\
\text { tecnologias na área ambiental; perdas estimadas por redução ao valor recuperável de ativos } \\
\text { ambientais; amortização, exaustão e depreciação; propaganda; gastos com aquisição de } \\
\text { créditos de carbono. }\end{array}$ \\
\hline
\end{tabular}

Fonte: elaborada pelos autores

$\mathrm{Na}$ coleta de dados, especialmente para a destinação da informação para despesa ou investimento, observou-se o tratamento dado pela empresa. Outro ponto importante é que algumas empresas divulgaram o valor de seus investimentos ou gastos ambientais junto com os de outras áreas, como infraestrutura ou produção. Nesses casos, o tratamento dado para a classificação da sentença foi de informação quantitativa não monetária, uma vez que não se sabia qual parcela daquele montante se referia à área ambiental.

As informações foram extraídas das DFPs, com base na busca e leitura de palavras- chave, sendo elas: ambient; poluent; resíduo; recicl; carbono; sustent; degrad; e ecoeficiente.

Para analisar os dados, utilizou-se a análise de conteúdo. Já a seleção da técnica estatística, realizada por testes paramétricos ou não paramétricos, depende dos resultados dos testes de Normalidade e Homogeneidade. O teste de Normalidade Univariada abrange o teste de Kolmogorov-Smirnov e o de Shapiro-Wilk. Já o teste de Homogeneidade de Variâncias foi realizado por meio do teste de Levene (Fávero, Belfiore, Silva \& Chan, 2009). Ambos os testes foram efetuados por meio do software SPSS.

Como os resultados dos testes de Normalidade Univariada e Homogeneidade de Variâncias rejeitaram as hipóteses nulas, para este estudo, utilizou-se o teste não paramétrico de Kruskal-Wallis, que considera $K$ amostras independentes. 


\section{Resultados}

Para analisar as informações financeiras ambientais, foi utilizada a métrica composta de sete categorias e trinta subcategorias. Durante a coleta de informações nas DFPs, foi necessário acrescentar o item "gastos com aquisição de créditos de carbono".

Nos anos analisados, as empresas evidenciaram um total de 595 sentenças, sendo 190, em 2011; 211, em 2012; e 194, em 2013. De modo geral, as categorias ambientais apresentaram diferenças no comportamento de sentenças divulgadas. As categorias de investimentos ambientais, ativos ambientais tangíveis e custo e/ou despesas ambientais mostraram um aumento na divulgação de informações financeiras no ano de 2012, se comparado a 2011, e redução, em relação a 2013. As categorias de ativos ambientais intangíveis, passivos e contingências ambientais e receitas apresentaram aumento gradativo nos anos, mostrando maior número de sentenças em 2013. A identificação da distribuição das sentenças nas categorias da métrica em Qualitativa (Q), Quantitativa Não Monetária (QNM) e Quantitativa Monetária (QM) está demonstrada na Tabela 4.

Tabela 4

\section{Número de sentenças por categoria}

\begin{tabular}{|c|c|c|c|c|c|c|c|c|c|}
\hline \multirow{2}{*}{ Categorias } & 2011 & 2012 & 2013 & 2011 & 2012 & 2013 & 2011 & 2012 & 2013 \\
\hline & Q & Q & Q & QNM & QNM & QNM & QM & QM & QM \\
\hline $\begin{array}{l}\text { Investimentos } \\
\text { Ambientais }\end{array}$ & 74 & 78 & 59 & 21 & 26 & 31 & 21 & 20 & 18 \\
\hline $\begin{array}{l}\text { Ativos Ambientais } \\
\text { Tangíveis }\end{array}$ & 6 & 4 & 8 & 2 & 2 & 0 & 2 & 5 & 2 \\
\hline $\begin{array}{l}\text { Ativos Ambientais } \\
\text { Intangíveis }\end{array}$ & 2 & 3 & 3 & 0 & 0 & 0 & 1 & 1 & 1 \\
\hline Ativos Contingentes & 0 & 0 & 0 & 0 & 0 & 0 & 0 & 0 & 0 \\
\hline $\begin{array}{l}\text { Passivos e } \\
\text { Contingências } \\
\text { Ambientais }\end{array}$ & 1 & 2 & 2 & 5 & 5 & 7 & 20 & 23 & 28 \\
\hline Receitas Ambientais & 1 & 1 & 3 & 0 & 0 & 0 & 1 & 1 & 1 \\
\hline $\begin{array}{l}\text { Custos e/ou } \\
\text { Despesas Ambientais }\end{array}$ & 27 & 30 & 22 & 2 & 6 & 5 & 4 & 4 & 4 \\
\hline Total & 111 & 118 & 97 & 30 & 39 & 43 & 49 & 54 & 54 \\
\hline
\end{tabular}

Legenda: Q - Qualitativa, QNM - Qualitativa Não Monetária e QM - Qualitativa Monetária

Fonte: elaborada pelos autores

Entre as classificações de informações Qualitativas, o maior número de sentenças está em investimentos ambientais, seguido de custos e/ou despesas ambientais. Encontra-se na última posição o item receitas ambientais e contingências ambientais. Vale ressaltar que os ativos contingentes não foram mencionados em nenhuma das DFPs. Em relação à quantidade de sentenças das informações Quantitativas Não Monetárias, foram encontradas maior evidenciação em investimentos ambientais e menor em ativos ambientais intangíveis e receitas ambientais, ambas zeradas.

Já entre as Quantitativas Monetárias, a maior quantidade de sentenças está na subcategoria de passivos e contingências ambientais, estando novamente os ativos ambientais intangíveis e as receitas ambientais nas últimas posições. A categoria Investimentos Ambientais aumentou o disclosure de informações Quantitativas Monetárias e reduziu as Qualitativas, o que pode demonstrar uma melhor qualidade de informação no decorrer dos anos do estudo, especialmente em 2013 (Tabela 5). 
Tabela 5

Soma dos valores monetários nos 3 anos do estudo

\begin{tabular}{|c|c|c|c|c|}
\hline & 2011 & 2012 & 2013 & \\
\hline Subcategorias & $\begin{array}{c}\text { Total } \\
\text { (R\$ Mil) }\end{array}$ & $\begin{array}{c}\text { Total } \\
\text { (R\$ Mil) }\end{array}$ & $\begin{array}{c}\text { Total } \\
\text { (R\$ Mil) }\end{array}$ & Total (R\$ Mil) \\
\hline Investimentos ambientais & $108.937 .177,50$ & $4.755 .425,69$ & $4.975 .545,70$ & $118.668 .148,89$ \\
\hline Ativos ambientais tangíveis & 79,89 & $154.330,04$ & $160.608,89$ & $315.018,82$ \\
\hline $\begin{array}{l}\text { Ativos ambientais } \\
\text { intangíveis }\end{array}$ & $7.437,00$ & $9.664,00$ & $9.317,00$ & $26.418,00$ \\
\hline Ativos contingentes & 0,00 & 0,00 & 0,00 & 0,00 \\
\hline $\begin{array}{l}\text { Passivos e contingências } \\
\text { ambientais }\end{array}$ & $63.426 .664,00$ & $129.840 .048,00$ & $66.571 .782,00$ & $259.838 .494,00$ \\
\hline Receitas ambientais & $6.950,00$ & $2.862,00$ & $8.400,00$ & $18.212,00$ \\
\hline $\begin{array}{l}\text { Custos e/ou despesas } \\
\text { ambientais }\end{array}$ & $52.687,00$ & $51.227,00$ & $36.489,00$ & $140.403,00$ \\
\hline
\end{tabular}

Fonte: elaborada pelos autores

O maior valor está na categoria de passivos e contingências ambientais ( $\mathrm{R} \$ 259,8$ bilhões), seguido de investimentos ambientais ( $\mathrm{R} \$ 118,6$ bilhões). A categoria que recebeu menos recursos, com exceção dos ativos contingentes, foi receitas ambientais, com $\mathrm{R} \$ 18,2$ milhões.

As subcategorias diferenciam o tipo de informação e esclarecem a disposição dos recursos nas categorias de informações financeiras ambientais em conformidade com a apresentação de cada empresa. $\mathrm{Na}$ Tabela 6, são apresentadas as classificações de evidências das subcategorias vinculadas à categoria investimentos ambientais.

Tabela 6

\section{Evidências das subcategorias vinculadas à categoria Investimentos Ambientais}

\begin{tabular}{|c|c|c|c|c|c|c|c|c|c|}
\hline \multirow{2}{*}{ Investimentos ambientais } & \multicolumn{3}{|c|}{2011} & \multicolumn{3}{|c|}{2012} & \multicolumn{3}{|c|}{2013} \\
\hline & Q & QNM & QM & Q & QNM & QM & Q & QNM & QM \\
\hline $\begin{array}{l}\text { Manutenção/modificação nos processos } \\
\text { operacionais para a melhoria do meio ambiente }\end{array}$ & 17 & 9 & 11 & 17 & 11 & 9 & 21 & 15 & 7 \\
\hline $\begin{array}{l}\text { Recuperação de ambientes degradados pela } \\
\text { empresa ou por outras }\end{array}$ & 2 & 1 & 4 & 1 & 0 & 4 & 1 & 0 & 2 \\
\hline $\begin{array}{l}\text { Educação ambiental para empregados, } \\
\text { terceirizados, autônomos e administradores da } \\
\text { entidade }\end{array}$ & 5 & 0 & 1 & 6 & 0 & 0 & 5 & 1 & 0 \\
\hline Educação ambiental para a comunidade & 8 & 2 & 1 & 16 & 2 & 1 & 9 & 6 & 3 \\
\hline Programas e projetos ambientais & 42 & 9 & 4 & 38 & 13 & 6 & 23 & 9 & 6 \\
\hline Total & 74 & 21 & 21 & 78 & 26 & 20 & 59 & 31 & 18 \\
\hline
\end{tabular}

Legenda: Q - Qualitativa, QNM - Qualitativa Não Monetária e QM - Qualitativa Monetária

Fonte: elaborada pelos autores

Na categoria de Investimentos Ambientais, percebeu-se redução das informações Qualitativas em 2013. Contudo, ocorreu um aumento nas Quantitativas Não Monetárias, o que pode demonstrar uma melhor evidenciação por parte das empresas. As Quantitativas Monetárias apresentaram queda nos anos do estudo. Observa-se, ainda, que as subcategorias mais citadas foram programas e projetos ambientais e manutenção/modificação nos processos operacionais para a melhoria do meio ambiente, respectivamente. 
A Tabela 7 demonstra a evidenciação das informações financeiras monetárias da amostra referente à categoria Investimento Ambiental e subcategorias.

Tabela 7

Valores monetários evidenciados na categoria Investimentos Ambientais

\begin{tabular}{|c|c|c|c|c|c|c|}
\hline \multirow{2}{*}{$\begin{array}{l}\text { Investimentos } \\
\text { Ambientais }\end{array}$} & \multicolumn{2}{|c|}{2011} & \multicolumn{2}{|c|}{2012} & \multicolumn{2}{|c|}{2013} \\
\hline & $\begin{array}{c}\text { Total } \\
\text { (R\$ Mil) }\end{array}$ & $\begin{array}{l}\text { Média } \\
\text { (R\$ Mil) }\end{array}$ & $\begin{array}{c}\text { Total } \\
\text { (R\$ Mil) }\end{array}$ & $\begin{array}{l}\text { Média } \\
\text { (R\$ Mil) }\end{array}$ & $\begin{array}{c}\text { Total } \\
\text { (R\$ Mil) }\end{array}$ & $\begin{array}{l}\text { Média } \\
\text { (R\$ Mil) }\end{array}$ \\
\hline $\begin{array}{l}\text { Manutenção/ } \\
\text { modificação } \\
\text { nos processos } \\
\text { operacionais } \\
\text { para a melhoria } \\
\text { ambiental }\end{array}$ & $3.410 .903,00$ & $310.082,09$ & $3.030 .398,00$ & $336.710,89$ & $3.286 .120,00$ & $410.765,00$ \\
\hline $\begin{array}{l}\text { Recuperação } \\
\text { de ambientes } \\
\text { degradados pela } \\
\text { empresa ou por } \\
\text { outras }\end{array}$ & $474.918,70$ & $118.729,68$ & $598.839,00$ & $199.613,00$ & $493.500,00$ & $164.500,00$ \\
\hline $\begin{array}{l}\text { Educação } \\
\text { ambiental para } \\
\text { empregados, } \\
\text { terceirizados, } \\
\text { autônomos e } \\
\text { administradores } \\
\text { da entidade }\end{array}$ & 29,00 & 29,00 & 0,00 & 0,00 & 0,00 & 0,00 \\
\hline $\begin{array}{l}\text { Educação } \\
\text { ambiental para a } \\
\text { comunidade }\end{array}$ & 172,00 & 172,00 & $20.206,00$ & $10.103,00$ & $275.266,00$ & $91.755,33$ \\
\hline $\begin{array}{l}\text { Programas } \\
\text { e projetos } \\
\text { ambientais }\end{array}$ & $105.051 .154,80$ & 26.262.788,70 & $1.105 .982,69$ & $221.196,54$ & $920.659,70$ & $153.443,28$ \\
\hline Total & $108.937 .177,50$ & $26.691 .801,47$ & 4.755.425,69 & $767.623,43$ & $4.975 .545,70$ & $820.463,62$ \\
\hline
\end{tabular}

Fonte: elaborada pelos autores

No ano de 2011, a primeira subcategoria obteve um total de $\mathrm{R} \$ 3,4$ bilhões, sendo a média de investimento na manutenção/modificação nos processos operacionais para a melhoria do meio ambiente de $\mathrm{R} \$ 310$ milhões. A recuperação de ambientes degradados apresentou média de $\mathrm{R} \$ 118$ milhões e seu total foi de $\mathrm{R} \$ 474$ milhões, contudo, uma só empresa é responsável por $71 \%$ dos investimentos, com $\mathrm{R} \$ 337$ milhões. As subcategorias de Educação Ambiental foram contempladas monetariamente por apenas uma empresa, por esse motivo o valor total e a média são iguais. A subcategoria que apresentou, em 2011, maior investimento foi a de programas e projetos ambientais, com $\mathrm{R} \$ 105$ bilhões.

A subcategoria que angariou maior valor de investimentos no ano de 2012 foi manutenção/modificação nos processos operacionais para a melhoria do meio ambiente, com um total de $\mathrm{R} \$ 3,03$ bilhões, seguido de programas e projetos ambientais, com $\mathrm{R} \$ 1,1$ bilhão. A subcategoria educação ambiental para empregados, terceirizados, autônomos e administradores da entidade não foi citada nenhuma vez no referido ano.

Em 2013, repetindo o ano anterior, a subcategoria que possui mais investimentos é de manutenção/ modificação nos processos operacionais para a melhoria do meio ambiente, com $\mathrm{R} \$ 3,2$ bilhões. A subcategoria educação ambiental para empregados, terceirizados, autônomos e administradores da entidade não foi citada nenhuma vez, novamente.

Pode-se observar que o valor total investido é mais elevado em 2011, com $\mathrm{R} \$ 108$ bilhões. $\mathrm{O}$ ano de 2012 apresentou $\mathrm{R} \$ 4,7$ bilhões, e 2013, R \$4,9 bilhões. O ano de 2012 representa 4\% do valor de 2011, e de 2012 a 2013 houve um aumento de cerca de R\$200 milhões. 
As empresas podem, ou não, evidenciar seus ativos ambientais separadamente da totalidade de ativos, contudo, poucas empresas na amostra escolhida o fizeram (Tabela 8).

Tabela 8

Evidências das subcategorias vinculadas à categoria Ativos Ambientais Tangíveis

\begin{tabular}{lccccccccc}
\hline \multicolumn{1}{c}{ Ativos Ambientais Tangíveis } & \multicolumn{3}{c}{$\mathbf{2 0 1 1}$} & & $\mathbf{2 0 1 2}$ & & $\mathbf{2 0 1 3}$ \\
\cline { 2 - 9 } & Q & QNM & QM & Q & QNM & QM & Q & QNM & QM \\
\hline $\begin{array}{l}\text { Máquinas/equipamentos/instalações para redução } \\
\text { de resíduos poluentes }\end{array}$ & 6 & 2 & 2 & 4 & 2 & 4 & 8 & 0 & 2 \\
\hline $\begin{array}{l}\text { Estoque de insumos e peças e acessórios } \\
\begin{array}{l}\text { utilizados no processo de redução ou eliminação } \\
\text { dos níveis de poluição }\end{array}\end{array}$ & 0 & 0 & 0 & 0 & 0 & 1 & 0 & 0 & 0 \\
\hline Total & 6 & 2 & 2 & 4 & 2 & 5 & 8 & 0 & 2 \\
\hline
\end{tabular}

Legenda: Q - Qualitativa, QNM - Qualitativa Não Monetária e QM - Qualitativa Monetária

Fonte: elaborada pelos autores

O comportamento das informações ambientais tangíveis variou de modo irregular entre as evidências Q, QNM e QM. O ano de 2012 foi o que apresentou mais sentenças Quantitativas Monetárias. Pode-se destacar que apenas a subcategoria máquinas/equipamentos/instalações para redução de resíduos poluentes apresentou evidências em todos os anos e classificações. Na subcategoria estoque de insumos e peças e acessórios utilizados no processo de redução ou eliminação dos níveis de poluição, houve uma sentença em 2012. E nenhuma informação foi discutida acerca de máquinas/equipamentos/instalações para fabricação de subprodutos (Tabela 9).

Tabela 9

Valores monetários evidenciados na categoria de Ativos Ambientais Tangíveis

\begin{tabular}{lcccccc}
\hline \multicolumn{1}{c}{$\begin{array}{c}\text { Ativos Ambientais } \\
\text { Tangíveis }\end{array}$} & \multicolumn{2}{c}{2011} & \multicolumn{2}{c}{2012} & 2013 \\
\cline { 2 - 7 } & $\begin{array}{c}\text { Total } \\
\text { (R\$ Mil) }\end{array}$ & $\begin{array}{c}\text { Média } \\
\text { (R\$ Mil) }\end{array}$ & $\begin{array}{c}\text { Total } \\
\text { (R\$ Mil) }\end{array}$ & $\begin{array}{c}\text { Média } \\
\text { (R\$ Mil) }\end{array}$ & $\begin{array}{c}\text { Total } \\
\text { (R\$ Mil) }\end{array}$ & $\begin{array}{c}\text { Média } \\
\text { (R\$ Mil) }\end{array}$ \\
\hline $\begin{array}{l}\text { Máquinas/equipamentos/ } \\
\text { instalações para redução de } \\
\text { resíduos poluentes }\end{array}$ & 80,79 & 40,40 & $70.330,04$ & $17.582,51$ & $160.608,89$ & $53.536,30$ \\
\hline $\begin{array}{l}\text { Estoque de insumos e peças } \\
\text { e acessórios utilizados no } \\
\text { processo de redução ou } \\
\text { eliminação dos níveis de } \\
\text { poluição }\end{array}$ & 0,00 & 0,00 & $84.000,00$ & 0,00 & 0,00 & 0,00 \\
\hline Total & & & & & & \\
\hline
\end{tabular}

Fonte: elaborada pelos autores

Nesta categoria, no ano de 2011, a única subcategoria contemplada foi a de máquinas/ equipamentos/ instalações para redução de resíduos poluentes, no valor de $\mathrm{R} \$ 80,7$ mil. Em 2012, o total de investimentos na categoria foi de $\mathrm{R} \$ 154,3$ milhões, e em 2013, R \$160,6 milhões, a diferença foi de R \$6,3 milhões. Contudo, observa-se que o valor em 2012 foi fracionado entre as subcategorias Máquinas/equipamentos/instalações para redução de resíduos poluentes e Estoque de insumos e peças e acessórios utilizados no processo de redução/eliminação de poluição, sendo que em 2013 apenas a primeira recebeu valores monetários. Os Ativos Ambientais Intangíveis foram evidenciados pelas empresas da amostra, conforme mostram as tabelas 10 e 11 . 
Tabela 10

Evidências das subcategorias vinculadas à categoria Ativos Ambientais Intangíveis

\begin{tabular}{|c|c|c|c|c|c|c|c|c|c|}
\hline \multirow{2}{*}{ Ativos Ambientais Intangíveis } & \multicolumn{3}{|c|}{2011} & \multicolumn{3}{|c|}{2012} & \multicolumn{3}{|c|}{2013} \\
\hline & Q & QNM & QM & Q & QNM & QM & Q & QNM & QM \\
\hline Marca, licença e/ou patente & 1 & 0 & 1 & 1 & 0 & 1 & 2 & 0 & 1 \\
\hline $\begin{array}{l}\text { Desenvolvimento de produtos e tecnologias } \\
\text { na área ambiental }\end{array}$ & 1 & 0 & 0 & 2 & 0 & 0 & 1 & 0 & 0 \\
\hline Total & 2 & 0 & 1 & 3 & 0 & 1 & 3 & 0 & 1 \\
\hline
\end{tabular}

Legenda: Q - Qualitativa, QNM - Qualitativa Não Monetária e QM - Qualitativa Monetária

Fonte: elaborada pelos autores

A categoria Ativo Ambiental Intangível apresentou maior número de sentenças na subcategoria marca, licença e/ou patente, apresentando evolução de uma sentença Qualitativa em 2013 e mantendo inalterada as demais evidências.

Tabela 11

Valores monetários evidenciados na categoria de Ativos Ambientais Intangíveis

\begin{tabular}{lcccccc}
\hline \multirow{2}{*}{$\begin{array}{l}\text { Ativos Ambientais } \\
\text { Intangíveis }\end{array}$} & \multicolumn{2}{c}{2011} & \multicolumn{2}{c}{2012} & \multicolumn{2}{c}{2013} \\
\cline { 2 - 7 } & $\begin{array}{c}\text { Total } \\
\text { (R\$ Mil) }\end{array}$ & $\begin{array}{c}\text { Média } \\
\text { (R\$ Mil) }\end{array}$ & $\begin{array}{c}\text { Total } \\
\text { (R\$ Mil) }\end{array}$ & $\begin{array}{c}\text { Média } \\
\text { (R\$ Mil) }\end{array}$ & $\begin{array}{c}\text { Total } \\
\text { (R\$ Mil) }\end{array}$ & $\begin{array}{c}\text { Média } \\
\text { (R\$ Mil) }\end{array}$ \\
\hline Marca, licença e/ou patente & $7.437,00$ & $7.437,00$ & $9.664,00$ & $9.664,00$ & $9.317,00$ & $9.317,00$ \\
\hline Total & $7.437,00$ & $7.437,00$ & $9.664,00$ & $9.664,00$ & $9.317,00$ & $9.317,00$ \\
\hline
\end{tabular}

Fonte: elaborada pelos autores

$\mathrm{Na}$ amostra de 46 empresas, apenas uma divulgou o valor de marca, licença e/ou patente. Nota-se que nos três anos o mesmo valor se repete nas colunas total e média. Não foram apurados, monetariamente, pelas empresas, os valores referentes ao desenvolvimento de produtos e tecnologias na área ambiental. A sentença divulgada aumentou, de 2011 para 2012, em R\$2,22 milhões e reduziu R \$347 mil, em 2013.

Tabela 12

Evidências das subcategorias vinculadas à Categoria Passivos e Contingências Ambientais

\begin{tabular}{lccccccccc}
\hline Passivos e Contingências & \multicolumn{3}{c}{$\mathbf{2 0 1 1}$} & & $\mathbf{2 0 1 2}$ & \multicolumn{2}{c}{$\mathbf{2 0 1 3}$} \\
\cline { 2 - 12 } Ambientais & Q & QNM & QM & Q & QNM & QM & Q & QNM & QM \\
\hline Passivo e Provisão provável & 0 & 2 & 17 & 1 & 2 & 18 & 1 & 3 & 23 \\
\hline Provisão possível & 1 & 1 & 2 & 1 & 1 & 3 & 1 & 2 & 3 \\
\hline Provisão remota & 0 & 1 & 1 & 0 & 1 & 2 & 0 & 1 & 2 \\
\hline Provisão sem probabilidade & 0 & 1 & 0 & 0 & 1 & 0 & 0 & 1 & 0 \\
\hline Total & $\mathbf{1}$ & $\mathbf{5}$ & $\mathbf{2 0}$ & $\mathbf{2}$ & $\mathbf{5}$ & $\mathbf{2 3}$ & $\mathbf{2}$ & $\mathbf{7}$ & $\mathbf{2 8}$ \\
\hline
\end{tabular}

Legenda: Q - Qualitativa, QNM - Qualitativa Não Monetária e QM - Qualitativa Monetária

Fonte: elaborada pelos autores

A categoria Passivo e Contingência Ambiental apresentou evolução positiva, no que tange ao valor total das evidências. A subcategoria passivo e provisão provável foi a que apresentou maior número de sentenças Quantitativas Monetárias (Tabela 12). 
As informações das provisões, além de constarem em notas explicativas, também são encontradas no balanço patrimonial, o que justifica a maior quantidade de evidências Quantitativas Monetárias nesta categoria (Tabela 13).

Tabela 13

Valores monetários evidenciados na categoria de Passivos e Contingências Ambientais

\begin{tabular}{lcccccc}
\hline $\begin{array}{l}\text { Passivos e } \\
\begin{array}{l}\text { Contingências } \\
\text { Ambientais }\end{array}\end{array}$ & $\begin{array}{c}\text { Total } \\
\text { (R\$ Mil) }\end{array}$ & $\begin{array}{c}\text { Média } \\
\text { (R\$ Mil) }\end{array}$ & $\begin{array}{c}\text { Total } \\
\text { (R\$ Mil) }\end{array}$ & $\begin{array}{c}\text { Média } \\
\text { (R\$ Mil) }\end{array}$ & $\begin{array}{c}\text { Total } \\
\text { (R\$ Mil) }\end{array}$ & $\begin{array}{c}\text { Média } \\
\text { (R\$ Mil) }\end{array}$ \\
\cline { 2 - 7 } $\begin{array}{l}\text { Passivo e provisão } \\
\text { provável }\end{array}$ & $63.227 .094,00$ & $3.512 .616,33$ & $128.920 .505,00$ & $6.785 .289,74$ & $63.261 .578,00$ & $2.635 .899,08$ \\
\hline Provisão possível & $198.378,00$ & $99.189,00$ & $906.287,00$ & $302.095,67$ & $3.308 .558,00$ & $827.139,50$ \\
\hline Provisão remota & $1.192,00$ & $1.192,00$ & $13.256,00$ & $6.628,00$ & $1.646,00$ & $1.646,00$ \\
\hline Total & $\mathbf{6 3 . 4 2 6 . 6 6 4 , 0 0}$ & $\mathbf{3 . 6 1 2 . 9 9 7 , 3 3}$ & $\mathbf{1 2 9 . 8 4 0 . 0 4 8 , 0 0}$ & $\mathbf{7 . 0 9 4 . 0 1 3 , 4 0}$ & $\mathbf{6 6 . 5 7 1 . 7 8 2 , 0 0}$ & $\mathbf{3 . 4 6 4 . 6 8 4 , 5 8}$ \\
\hline
\end{tabular}

Fonte: elaborada pelos autores

Em valores monetários, pode-se afirmar que a maior incidência de passivos e contingências ambientais foi em 2012, com R $\$ 129,8$ milhões, sendo $\mathrm{R} \$ 128,9$ milhões de passivo e provisão provável. Em seguida, foi o ano de 2013 e depois 2011. A média da categoria em 2011 foi de R \$3,6 bilhões. Em 2012, ocorreu um aumento na média, de 50,94\%, com o valor de R \$7,09 bilhões, e, em 2013, houve uma queda de $48,84 \%$, se comparado a 2012 , com valor de R $\$ 3,4$ bilhões. Salienta-se que esses valores são encontrados pela média, ou seja, há diferenças significativas entre a quantia provisionada por uma empresa em relação a outra. $\mathrm{O}$ item provisão sem probabilidade não foi computado. As receitas ambientais foram pouco mencionadas nas DFPs (Tabela 14).

Tabela 14

Evidências das subcategorias vinculadas à categoria Receitas Ambientais

\begin{tabular}{lccccccccc}
\hline \multirow{2}{*}{ Receitas Ambientais } & \multicolumn{3}{c}{$\mathbf{2 0 1 1}$} & & $\mathbf{2 0 1 2}$ & & $\mathbf{2 0 1 3}$ \\
\cline { 2 - 10 } & Q & QNM & QM & Q & QNM & QM & Q & QNM & QM \\
\hline $\begin{array}{l}\text { Venda de produtos/subprodutos de } \\
\text { linha sustentável }\end{array}$ & 0 & 0 & 0 & 1 & 0 & 0 & 2 & 0 & 0 \\
\hline Venda de resíduos & 1 & 0 & 1 & 0 & 0 & 1 & 1 & 0 & 1 \\
\hline Total & 1 & 0 & 1 & 1 & 0 & 1 & 3 & 0 & 1 \\
\hline
\end{tabular}

Legenda: Q - Qualitativa, QNM - Qualitativa Não monetária e QM - Qualitativa Monetária

Fonte: elaborada pelos autores

As empresas não evidenciaram sentenças nas subcategorias venda de material reciclável e venda de créditos de carbono. Em relação às demais, a mais evidenciada nos três anos foi a venda de resíduos, e ocorreu uma evolução em 2013 nas sentenças qualitativas referente à venda de produtos/subprodutos de linha sustentável (Tabela 15). 
Tabela 15

Valores monetários evidenciados na categoria de Receitas Ambientais

\begin{tabular}{lcccccc}
\hline \multirow{2}{*}{ Receitas Ambientais } & \multicolumn{2}{c}{2011} & \multicolumn{2}{c}{2012} & \multicolumn{2}{c}{2013} \\
\cline { 2 - 7 } & $\begin{array}{c}\text { Total } \\
\text { (R\$ Mil) }\end{array}$ & $\begin{array}{c}\text { Média } \\
\text { (R\$ Mil) }\end{array}$ & $\begin{array}{c}\text { Total } \\
\text { (R\$ Mil) }\end{array}$ & $\begin{array}{c}\text { Média } \\
\text { (R\$ Mil) }\end{array}$ & $\begin{array}{c}\text { Total } \\
\text { (R\$ Mil) }\end{array}$ & $\begin{array}{c}\text { Média } \\
\text { (R\$ Mil) }\end{array}$ \\
\hline Venda de resíduos & $6.950,00$ & $6.950,00$ & $2.862,00$ & $2.862,00$ & $8.400,00$ & $8.400,00$ \\
\hline Total & $6.950,00$ & $6.950,00$ & $2.862,00$ & $2.862,00$ & $8.400,00$ & $8.400,00$ \\
\hline
\end{tabular}

Fonte: elaborada pelos autores

A evidenciação de valores nas receitas ambientais ocorreu por parte de uma única empresa, mais especificamente na venda de resíduos, tendo, em 2011, obtido uma receita de $\mathrm{R} \$ 6,9$ milhões; em 2012, $\mathrm{R} \$ 2,8$ milhões; e, em 2013, $\mathrm{R} \$ 8,4$ milhões. As despesas e/ou custos ambientais estão discriminados nas tabelas 16 e 17.

Tabela 16

Evidências das subcategorias vinculadas à categoria Custos e/ou Despesas Ambientais

\begin{tabular}{|c|c|c|c|c|c|c|c|c|c|}
\hline \multirow{2}{*}{ Custos e/ou Despesas Ambientais } & \multicolumn{3}{|c|}{2011} & \multicolumn{3}{|c|}{2012} & \multicolumn{3}{|c|}{2013} \\
\hline & Q & QNM & QM & Q & QNM & QM & Q & QNM & QM \\
\hline $\begin{array}{l}\text { Manutenção nos processos operacionais para a } \\
\text { melhoria do meio ambiente }\end{array}$ & 1 & 1 & 1 & 2 & 2 & 1 & 1 & 1 & 1 \\
\hline Recuperação de ambientes degradados & 2 & 1 & 1 & 1 & 2 & 1 & 1 & 2 & 2 \\
\hline Programas e projetos ambientais & 1 & 0 & 0 & 0 & 0 & 0 & 0 & 0 & 0 \\
\hline Licenciamentos e/ou certificações & 16 & 0 & 1 & 20 & 0 & 0 & 16 & 0 & 0 \\
\hline $\begin{array}{l}\text { Gastos com pesquisa para desenvolvimento de } \\
\text { produtos e tecnologias na área ambiental }\end{array}$ & 5 & 0 & 0 & 5 & 2 & 1 & 3 & 2 & 1 \\
\hline Amortização, exaustão e depreciação & 1 & 0 & 1 & 1 & 0 & 1 & 0 & 0 & 0 \\
\hline Gastos com aquisição de créditos de carbono & 1 & 0 & 0 & 1 & 0 & 0 & 1 & 0 & 0 \\
\hline Total & 27 & 2 & 4 & 30 & 6 & 4 & 22 & 5 & 4 \\
\hline
\end{tabular}

Legenda: Q - Qualitativa, QNM - Qualitativa Não Monetária e QM - Qualitativa Monetária

Fonte: elaborada pelos autores

A métrica utilizada para diferenciar investimento ambiental de custos e/ou despesa ambiental, optou-se pelo tratamento dado pela empresa. As subcategorias mais evidenciadas foram licenciamentos e/ou certificações ambientais e gastos com pesquisa para desenvolvimento de produtos e tecnologias na área ambiental, respectivamente. Das doze subcategorias, cinco não receberam nenhuma sentença, sendo elas: educação ambiental para empregados, terceirizados, autônomos e administradores da entidade; educação ambiental para a comunidade, consultoria para elaboração de Estudo de Impacto Ambiental (EIA) e Relatório de Impacto Ambiental (Rima); perdas estimadas por redução ao valor recuperável de ativos ambientais; e propaganda. Pode-se observar que a maior parte das informações que dividem espaço entre as categorias de Investimento ou Despesa/Custo foi alocada na primeira, sendo respeitada a posição da empresa em relação ao evento. 
Tabela 17

Valores monetários evidenciados na categoria Custos e/ou Despesas Ambientais

\begin{tabular}{|c|c|c|c|c|c|c|}
\hline \multirow{2}{*}{$\begin{array}{c}\text { Custos e/ou Despesas } \\
\text { Ambientais }\end{array}$} & \multicolumn{2}{|c|}{2011} & \multicolumn{2}{|c|}{2012} & \multicolumn{2}{|c|}{2013} \\
\hline & $\begin{array}{c}\text { Total } \\
\text { (R\$ Mil) }\end{array}$ & $\begin{array}{l}\text { Média } \\
\text { (R\$ Mil) }\end{array}$ & $\begin{array}{c}\text { Total } \\
\text { (R\$ Mil) }\end{array}$ & $\begin{array}{l}\text { Média } \\
(\mathrm{R} \$ \text { Mil) }\end{array}$ & $\begin{array}{c}\text { Total } \\
\text { (R\$ Mil) }\end{array}$ & $\begin{array}{l}\text { Média } \\
\text { (R\$ Mil) }\end{array}$ \\
\hline $\begin{array}{l}\text { Manutenção nos processos } \\
\text { operacionais para a } \\
\text { melhoria do meio ambiente }\end{array}$ & $24.327,00$ & $24.327,00$ & $27.326,00$ & $27.326,00$ & $23.999,00$ & $23.999,00$ \\
\hline $\begin{array}{l}\text { Recuperação de ambientes } \\
\text { degradados }\end{array}$ & $6.860,00$ & $6.860,00$ & $23.472,00$ & $23.472,00$ & $10.390,00$ & $5.195,00$ \\
\hline $\begin{array}{l}\text { Licenciamentos e/ou } \\
\text { certificações ambientais }\end{array}$ & $21.500,00$ & $21.500,00$ & 0,00 & 0,00 & 0,00 & 0,00 \\
\hline $\begin{array}{l}\text { Gastos com pesquisa } \\
\text { para desenvolvimento de } \\
\text { produtos e tecnologias na } \\
\text { área ambiental }\end{array}$ & 0,00 & 0,00 & 429,00 & 429,00 & $2.100,00$ & $2.100,00$ \\
\hline Total & $52.687,00$ & $52.687,00$ & $51.227,00$ & $51.227,00$ & $36.489,00$ & $31.294,00$ \\
\hline
\end{tabular}

Fonte: elaborada pelos autores

Apesar de a categoria Custos e/ou Despesas Ambientais ser a que possui maior número de subcategorias, não é nela que foi observada a maior evidenciação de sentenças monetárias.

Das 12 subcategorias, apenas cinco apresentam valores especificados pelas empresas; sendo elas: manutenção nos processos operacionais para a melhoria do meio ambiente, recuperação de ambientes degradados; licenciamentos e/ou certificações ambientais; e gastos com pesquisa para desenvolvimento de produtos e tecnologias na área ambiental; e amortização, exaustão e depreciação. Esta última, apesar de apresentar resultado $\mathrm{R} \$ 0,00$, trata-se de valor divulgado, uma vez que informa que nada foi amortizado até esta data. Com exceção de gastos com pesquisa, as demais subcategorias aumentaram o disclosure dos custos/despesas em 2012, havendo redução em 2013.

As empresas foram classificadas por potencial de poluição; conforme Anexo VIII da Lei 10.165 de 2000. As empresas foram alocadas nas seguintes categorias: alto, médio, pequeno e não poluidor. A Tabela 18 demonstra as médias por classificação de acordo com o potencial de poluição. Ressalta-se que a amostra de alto potencial poluidor é composta de 10 empresas, de médio, por 8 empresas, pequeno, por 5 empresas, e 23 empresas não poluidoras.

Tabela 18

Médias de disclosure

\begin{tabular}{ccc}
\hline Potencial poluidor & Média dos três anos por empresa & Média de sentenças por ano \\
\hline Alto & 8,30 & 83 \\
\hline Médio & 6,75 & 54 \\
\hline Pequeno & 2,93 & 15 \\
\hline Não poluidor & 2,06 & 47 \\
\hline
\end{tabular}

Fonte: elaborada pelos autores

O número de sentenças na média por ano lidera as empresas de alto impacto ambiental, seguida das de médio, não poluidoras e de pequeno impacto ambiental. Contudo, quando se realiza a média por empresa, os dois últimos colocados invertem as posições, sendo as empresas não poluidoras as que menos divulgam informações ambientais. 
$\mathrm{Na}$ amostra, constatou-se que: (i) a média de divulgação das 10 empresas classificadas como de alto impacto ambiental varia de 0,67 a 16 sentenças; (ii) a média de divulgação das 8 empresas classificadas em médio impacto varia de 0,00 a 27,33 sentenças; (iii) as 5 empresas classificadas em pequeno impacto ambiental divulgaram entre 0,33 e 5,67 sentenças; e (iv) as 23 empresas consideradas como não poluidoras apresentaram entre 0,00 e 12,33 sentenças.

Os testes não paramétricos segundo, Fávero et al. (2009, p. 144), "não exigem suposições numerosas ou restringentes em relação à distribuição de dados". Os autores (2009) afirmam que "esses métodos são matematicamente simples, de fácil execução e aplicam-se não só a dados quantitativos, mas também a dados de natureza nominal e ordinal".

O comportamento da amostra indica qual teste deve ser aplicado, no caso deste estudo, " $\mathrm{K}$ " amostras independentes - ordinal, indica o teste de Kruskal-Wallis. A significância do teste foi de 0,000 (valor inferior a 0,01), o que leva à rejeição da hipótese nula e permite concluir que há diferenças nas distribuições das amostras, ou seja, reafirma que há diferenças no disclosure de informações financeiras nas empresas com diferentes potenciais de poluição. Os resultados do teste que considerou os três anos de estudo são apresentados na Tabela 19.

Tabela 19

Média do ranking pelo teste de Kruskal-Wallis

\begin{tabular}{cccc}
\hline Ranks & PPGU & N & Mean Rank \\
\hline \multirow{3}{*}{ Disclosure } & Alto & 30 & 106,28 \\
\cline { 2 - 4 } & Médio & 24 & 83,54 \\
\cline { 2 - 4 } & Pequeno & 15 & 62,77 \\
\cline { 2 - 4 } & Não poluidor & 69 & 50,09 \\
\hline
\end{tabular}

Fonte: elaborada pelos autores

Por meio do teste não paramétrico de Kruskal-Wallis, pode-se observar que há diferenças no nível de disclosure de informações financeiras ambientais, no que tange à classificação da Lei n. ${ }^{\circ}$ 10.165/2000 em alto, médio e pequeno impacto, sendo classificadas como não poluidoras aquelas não descritas na referida lei. No teste, pode-se perceber que as empresas de alto impacto ambiental são as que mais evidenciam informações financeiras ambientais em detrimento das não poluidoras, que evidenciam menos.

\section{Conclusão}

Esta pesquisa teve como objetivo analisar o disclosure voluntário das informações financeiras ambientais em empresas classificadas em setores com diferentes impactos ambientais. Para atingir este objetivo, foram analisadas as DFPs das empresas que compõem o Índice IBrX-50, referentes ao período de 2011 a 2013. Com a análise de conteúdo obtida a partir da métrica proposta, os resultados demonstraram que foram evidenciadas 595 sentenças financeiras ambientais, sendo 190, em 2011, 211, em 2012, e 194, em 2013.

Ao identificar as informações financeiras ambientais nas DFPs, a categoria mais evidenciada foi a de Investimentos Ambientais, com 348 sentenças, representando 58\% das informações divulgadas. A categoria na qual as empresas evidenciaram mais recursos de Passivos e Contingências Ambientais, com R \$259,84 bilhões.

Em relação à evidenciação nas subcategorias, na categoria Investimentos Ambientais, a que apresentou mais sentenças foi Programas e Projetos Ambientais, sendo também o maior valor investido, R \$107,07 bilhões. Na categoria Ativos Ambientais Tangíveis, a maior evidenciação ocorreu na subcategoria máquinas/equipamentos/instalações para redução de resíduos poluentes, na qual ocorreu também a maior aplicação de recursos, $\mathrm{R} \$ 231,01$ milhões. A subcategoria marca, licença e/ou patente foi a mais 
divulgada em ativos ambientais intangíveis, sendo a única que divulgou valores monetários. Quanto à categoria Ativos Contingentes, não houve divulgação. A maior evidenciação na categoria Passivos e Contingências Ambientais foi a subcategoria passivo e provisão provável, com 67 sentenças, sendo também a que possui maior valor evidenciado, $\mathrm{R} \$ 225,41$ bilhões. Nas Receitas Ambientais, a venda de resíduos foi a que melhor representou a categoria, com cinco sentenças, sendo esta a única subcategoria que evidenciou valores monetários. E na categoria Custos e/ou Despesas Ambientais, a subcategoria licenciamentos e/ou certificações ambientais foi a que mais divulgou sentenças, contudo, a subcategoria que apresentou a maior aplicação de recursos nos anos do estudo foi a de manutenção nos processos operacionais para a melhoria do meio ambiente, com $\mathrm{R} \$ 75,65$ milhões.

Quanto ao disclosure médio por potencial de poluição, nos três anos, percebe-se a maior média nas empresas de alto impacto ambiental; na sequência, as de médio, pequeno e as não poluidoras. Contudo, se considerada a média de sentenças divulgadas por ano, observa-se que há uma média maior entre as não poluidoras, em vez das de pequeno impacto ambiental.

O teste não paramétrico de Kruskal-Wallis e os resultados demonstraram que, em relação ao disclosure de informações financeiras ambientais, as empresas de alto impacto ambiental estão na primeira colocação em evidenciação, seguida das de médio, pequeno e não poluidoras, confirmando a análise deste estudo. Foi possível perceber, diante dos resultados, que as empresas com alto potencial poluidor são as que mais divulgam informações.

\section{Referências}

Abreu, M. C. S.; Fernandes, J. S.; Assis, F. S. \& Silva Filho, J. C. L. (2008). Evolução da conduta ambiental de empresas siderúrgicas brasileiras sob a óptica dos relatórios de evidenciação ambiental. Revista Universo Contábil, 4(4), pp. 57-76. Recuperado de http://proxy.furb.br/ojs/index.php/universocontabil/article/view/1060.

Al-Khater, K. \& Naser, K. (2003). Users' perception of corporate social responsibility and accountability: evidence from an emerging economy. Managerial Auditing Journal, 18. DOI: $10.1108 / 02686900310482678$

Andrikopoulos, A. \& Kriklani, N. (2013). Environmental disclosure and financial characteristics of the Firm: The Case of Denmark. Corporate Social Responsibility and Environmental Management, 20, pp. 55-64. DOI: 10.1002/csr.1281

Bebbington, J. \& Larrinaga, C. (2014) Accounting and sustainable development: An exploration. Accounting, Organizations and Society. DOI: 10.1016/j.aos.2014.01.003

Belkaoui, (1976). A. The impact of the disclosure of the environmental effects of organizational behavior on the market. Financial Management, 5(4), pp. 26-31. Recuperado em http://www.jstor.org/stable/3665454

BM\&FBOVESPA. Índice Brasil 50 - IBrX 50 Recuperado em 23 agosto, 2014, de http://www.bmfbovespa. com.br/indices/ResumoIndice.aspx?Indice $=\mathrm{IBrX50 \& Opcao}=0 \&$ idioma $=\mathrm{pt}-\mathrm{br}$.

BRASIL. Lei n. 6.404, de 15 de dezembro de 1976. Dispõe sobre as Sociedades por Ações. Brasília, 15 de dezembro de 1976; $155^{\circ}$ da Independência e $88^{\circ}$ da República. Recuperado em: http://www.planalto.gov.br/ccivil_03/LEIS/L6404consol.htm

. Lei n. 10.165, de 27 de dezembro de 2000. Altera a Lei no 6.938, de 31 de agosto de 1981, que dispõe sobre a Política Nacional do Meio Ambiente, seus fins e mecanismos de formulação e aplicação, e dá outras providências. Brasília, 27 de dezembro de 2000; 179o da Independência e 112o da República. Recuperado em: http://www.planalto.gov.br/ccivil_03/Leis/L10165.htm 
Instrução CVM no 331, de 4 de abril de 2000. Dispõe sobre o registro de companhia para emissão e negociação de certificado de depósito de valores mobiliários - Programas de BDRs Níveis II e III com lastro em valores mobiliários de emissão de companhias abertas ou assemelhadas, com sede no exterior. Diário Oficial [da] União, 2000. Recuperado em: http://www.cvm.gov.br/legislacao/inst/inst331.html

. Lei n. 11.638, de 28 de dezembro de 2007. Altera e revoga dispositivos da Lei no 6.404, de 15 de dezembro de 1976, e da Lei no 6.385, de 7 de dezembro de 1976, e estende às sociedades de grande porte disposições relativas à elaboração e divulgação de demonstrações financeiras. Brasília, 28 de dezembro de 2007; 186o da Independência e 119o da República. Recuperado em: http://www. planalto.gov.br/ccivil_03/_ato2007-2010/2007/lei/111638.htm

. Lei n. 11.941, de 27 de maio de 2009. Altera a legislação tributária federal relativa ao parcelamento ordinário de débitos tributários; concede remissão nos casos em que especifica; institui regime tributário de transição, alterando o Decreto no 70.235, de 6 de março de 1972, as Leis nos 8.212, de 24 de julho de 1991, 8.213, de 24 de julho de 1991, 8.218, de 29 de agosto de 1991, 9.249, de 26 de dezembro de 1995, 9.430, de 27 de dezembro de 1996, 9.469, de 10 de julho de 1997, 9.532, de 10 de dezembro de 1997, 10.426, de 24 de abril de 2002, 10.480, de 2 de julho de 2002, 10.522, de 19 de julho de 2002, 10.887, de 18 de junho de 2004, e 6.404, de 15 de dezembro de 1976, o Decreto-Lei no 1.598, de 26 de dezembro de 1977, e as Leis nos8.981, de 20 de janeiro de 1995, 10.925, de 23 de julho de 2004, 10.637, de 30 de dezembro de 2002, 10.833, de 29 de dezembro de 2003, 11.116, de 18 de maio de 2005, 11.732, de 30 de junho de 2008, 10.260, de 12 de julho de 2001, 9.873, de 23 de novembro de 1999, 11.171, de 2 de setembro de 2005, 11.345, de 14 de setembro de 2006; prorroga a vigência da Lei no 8.989, de 24 de fevereiro de 1995; revoga dispositivos das Leis nos 8.383, de 30 de dezembro de 1991, e 8.620, de 5 de janeiro de 1993, do Decreto-Lei no 73, de 21 de novembro de 1966, das Leis nos 10.190, de 14 de fevereiro de 2001, 9.718, de 27 de novembro de 1998, e 6.938, de 31 de agosto de 1981, 9.964, de 10 de abril de 2000, e, a partir da instalação do Conselho Administrativo de Recursos Fiscais, os Decretos nos 83.304, de 28 de março de 1979, e 89.892, de 2 de julho de 1984, e o art. 112 da Lei no 11.196, de 21 de novembro de 2005; e dá outras providências. Brasília, 27 de maio de 2009; 188o da Independência e 121 o da República. Recuperado em: http://www.planalto.gov.br/ccivil_03/ato2007-2010/2009/lei/111941.htm

Burgwal, D. \& Vieira, R. (2014). Determinantes da divulgação ambiental em companhias abertas holandesas. Revista Contabilidade e Finanças, 25(64). DOI: http://dx.doi.org/10.1590/S151970772014000100006

Cho, C. H., Roberts, R. W. \& Patten, D. M. (2010). The language of US corporate environmental disclosure. Accounting, Organizations and Society, 35, pp. 431-443. DOI :10.1016/j.aos.2009.10.002

Cho, C. H.; Guidry, R. P.; Hageman, A. M. \& Patten, D. M. (2012). Do actions speak louder than words? An empirical investigation of corporate environmental reputation. Accounting, Organizations and Society, 37, pp.14-25. DOI: 10.1016/j.aos.2011.12.001

CFC. ITG 2004 - Interação da Entidade Com o Meio Ambiente: Normas Brasileiras de Contabilidade. Brasília: CFC, 2013. Recuperado em 30 outubro, 2014 de http://crcpb.org.br/noticias/itg-2004-interacao-da-entidade-com-o-meio-ambiente/

. NBC T 15 - Informações de Natureza Social e Ambiental: Resolução CFC nº 1.003/04, de 19 de agosto de 2004. Brasília: CFC, 2004. Recuperado em 18 maio, 2014 de <www.cfc.org.br/sisweb/sre/ docs/RES_1003.doc> 
COMISÃO DE VALORES MOBILIARIOS. Parecer de Orientação CVM n. 15, de 28 de dezembro de 1987. Procedimentos a serem observados pelas companhias abertas e auditores independentes na elaboração e publicação das demonstrações financeiras, do relatório da administração e do parecer de auditoria relativos aos exercícios sociais encerrados a partir de dezembro de 1987. Aprovado pelo colegiado em reunião de 28 de dezembro de 1987. Recuperado em: http://www.cvm.gov. $\mathrm{br} /$ legislacao/pare/pare015.html

INSTRUÇÃO CVM N. 331 de 04 de abril de 2000. Dispõe sobre o registro de companhia para emissão e negociação de certificado de depósito de valores mobiliários - Programas de BDRs Níveis II e III com lastro em valores mobiliários de emissão de companhias abertas ou assemelhadas, com sede no exterior. Aprovado pelo colegiado em reunião em 24 de março de 2000, com fundamento no disposto nos arts. 19 e 21 da Lei ${ }^{\circ}$ 6.385, de 7 de dezembro de 1976. Recuperado em: http://www.cvm.gov.br/legislacao/inst/inst331.html

. INSTRUÇÃO CVM N. 431 de 29 de maio de 2006. Altera as Instruções CVM nos 331 e 332, ambas de 4 de abril de 2000. Aprovado pelo colegiado em reunião em 26 de maio de 2006, com fundamento no disposto nos arts. 8o , inciso I, 19 e 21 da Lei no 6.385, de 7 de dezembro de 1976. Recuperado em: http://www.cvm.gov.br/export/sites/cvm/legislacao/inst/anexos/400/inst431 consolid.pdf

. INSTRUÇÃO CVM N. 469 de 02 de maio de 2008. Dispõe sobre a aplicação da Lei no 11.638, de 28 de dezembro de 2007. Altera as Instruções CVM n 247, de 27 de março de 1996 e 331, de 4 de abril de 2000. Aprovado pelo colegiado em reunião em 30 de abril de 2008, com fundamento nos $\$ \$ 3^{\circ}$ e $5^{\circ}$ do art. 177 da Lei no 6.404, de 15 de dezembro de 1976, combinados com os incisos II e IV do $\$ 1$ lo do art. 22 da Lei no 6.385, de 7 de dezembro de 1976, e tendo em vista, ainda, o disposto na Lei $\mathrm{n}^{\circ} 11.638$, de 28 de dezembro de 2007. Recuperado em: http://www.cvm.gov.br/legislacao/inst/inst469.html

INSTRUÇÃO CVM N. 480, de 7 dezembro de 2009 com as alterações introduzidas pelas instruções CVM No 488/10, 509/11, 511/11, 520/12, 525/12, 547/14, 552/14, 561/15, 567/15, 568/15 E 569/15. Dispõe sobre o registro de emissores de valores mobiliários admitidos à negociação em mercados regulamentados de valores mobiliários. Aprovado pelo Colegiado, em reunião realizada em 18 de novembro de 2009, com fundamento nos arts. 21 e 22 da Lei n ${ }^{\circ} 6.385$, de 7 de dezembro de 1976. Recuperado em: http://www.cvm.gov.br/legislacao/inst/inst480.html

CONSELHO INTERNACIONAL PARA RELATO INTEGRADO - IIRC. Relato Integrado. Brasil, 2014. Recuperado em 15 outubro, 2014, de <http://www.theiirc.org/wp-content/uploads/2014/04/13-12-08-THE-INTERNATIONAL-IR-FRAMEWORK-Portugese-final-1.pdf>

Deegan, C. (2002). The legitimizing effect of social and environmental disclosures - a theoretical foundation. Accounting, Auditing and Accountability Journal, 15(3), pp. 282-311. DOI: http://dx.doi. org/10.1108/09513570210435852

Epstein, M. J. \& Freedman, M. (1994). Social disclosure and the individual investor.

Accounting, Auditing \& Accountability Journal, 7 (4), pp. 94-109. DOI: http://dx.doi. org/10.1108/09513579410069867

Fávero, L. P.; Belfiore, P.; Silva, F. L. \& Chan, B. L. (2009) Análise de dados: modelagem multivariada para tomada de decisões. Rio de Janeiro: Elsevier.

Fernandes, S. M. (2013). Fatores que influenciam o disclosure ambiental: um estudo nas empresas brasileiras no período de 2006 a 2010. Revista Ambiente Contábil, 5(2), pp. 250 - 267. Recuperado de http:// periodicos.ufrn.br/ambiente/article/view/4159

Ferreira, D. D. M.; Borba, J. A. \& Rosa, C. A. (2014). As contingências ambientais das empresas estrangeiras que publicam suas demonstrações financeiras em IFRS no mercado norte americano. Revista Universo Contábil, 10(3), p. 134-154, jul./set. DOI:10.4270/RUC.2014323 
Freedman, M. \& Jaggi, B. (1986). Pollution disclosures, pollution performance and economic performance. Omega The International Journal of management Science, 10(2), pp. 167-176. Doi:10.1016/03050483(82)90051-2

Freitas, D. P. S. \& Oleiro, W. N. (2011). Contabilidade ambiental: A evidenciação nas demonstrações financeiras das empresas listadas na BM\&FBOVESPA. REUNIR - Revista de Administração, Contabilidade e Sustentabilidade, 1(2), pp. 65-81. DOI: http://dx.doi.org/10.18696/reunir.v1i2.29

Gray, R. (1992). Accounting and environmentalism: An exploration of the challenge of gently accounting for accountability, transparency and sustainability. Accountting, Organization and Society, 17(5), pp. 399 - 425. DOI: doi:10.1016/0361-3682(92)90038-T

Gray, R.; Walters, D.; Bebbington, J. \& Thompson, I. (1995). The greening of enterprise: An exploration of the (non) role of environmental accounting and environmental accountants in organisational change. Critical Perspectives on Accounting, 6(3), 211-239. DOI: doi:10.1006/cpac.1995.1021

Gray, R. (2002). The social accounting project and accounting organizations and society. Privileging engagement, imaginings, new accountings and pragmatism over critique? Accounting, Organizations and Society, 27(7), pp.687-708. DOI: doi:10.1016/S0361-3682(00)00003-9.

Harte, G. \& Owen, D. (1991). Environmental Disclosures in the Annual Reports of British Companies: A Research Note. Accounting, Auditing \& Accountability Journal, 4(3), 51-61. DOI: http://dx.doi. org/10.1108/09513579110144442

Imam, S. (2000). Corporate social performance reporting in Bangladesh. Managerial Auditing

Journal, 15, pp. 133-141. DOI: http://dx.doi.org/10.1108/02686900010319384.

Ingran, R. W. \& Frazier, K. (1980). Environmental Performance and corporate disclosure. Journal of Accounting Research, 18(2), pp. 614-622. DOI: 10.2307/2490597

INSTITUTO BRASILEIRO DE CONTADORES. Normas e Procedimentos de Auditoria -

NPA n. 11: estabelece os liames ente a Contabilidade e o meio ambiente. Balanço e Ecologia. São Paulo, 1996. Recuperado em 15 setembro, 2014 de <http://www.ibracon.com.br/ibracon/Portugues/detPublicacao.php?cod=124>

Milne, M. J. \& Adler, R. W. (1998). Exploring the reliability of social and environmental disclosures content analysis. Accounting, Auditing \& Accountability Journal, 12 (2), 237-256. DOI: http://dx.doi. org/10.1108/09513579910270138

Moreira, N. B. et al. (2014). Fatores que Impactam a Divulgação Voluntária de Informações Socioambientais na Percepção dos Gestores. REUNIR: Revista de Administração, Contabilidade e Sustentabilidade, 4(1), pp. 62-82. DOI: http://dx.doi.org/10.18696/reunir.v4i1.188

Parker, L. (2011). Twenty-one years of social and environmental accountability research: A coming of age. Accounting Forum, 35, pp. 1-10. DOI: http://dx.doi.org/10.1016/j.accfor.2010.11.001.

Ribeiro, M. S. (2006). Contabilidade ambiental. São Paulo: Saraiva.

Ribeiro, A. M.; Nascimento, L. F. \& van Bellen, H. M. (2009). Evidenciação ambiental: Uma análise comparativa multissetorial entre Brasil, Estados Unidos e Inglaterra. Revista Contemporânea de Economia e Gestão, 7(1), pp. 07-22. Doi:10.19094/116.

Rover, S.; Murcia, F. D.; Borba, J. A. \& Vicente, E. F. R. (2008) Divulgação de informações ambientais nas demonstrações Contábeis: um estudo exploratório sobre o disclosure das empresas brasileiras pertencentes a setores de alto impacto ambiental. RCO - Revista de Contabilidade e Organizações, 3(2), pp. 53 - 72. DOI: http://dx.doi.org/10.11606/rco.v2i3.34713 
Santos, P. S. A.; Vargas, A. J.; Almeida, D. M. \& Lavarda, C. E. F. (2012) Nível de disclosure verde e a reputação corporativa ambiental das companhias brasileiras de capital aberto. Revista Contemporânea de Contabilidade, 18, pp. 63-82. DOI: http://dx.doi.org/10.5007/2175-8069.2012v9n18p63.

SENADO FEDERAL - Projeto de Lei do Senado no 2012. Altera a Lei $n^{\circ} 6.404$, de 15 de dezembro de 1976, para dispor sobre a obrigatoriedade de Relatório de Sustentabilidade para as companhias ou sociedades anônimas. Senador VITAL DO RÊGO. Recuperado em: http://legis.senado.leg.br/mateweb/arquivos/mate-pdf/112619.pdf

Szuster, N.; Cardoso, R. L.; Szuster, F.R.; Szuster, F. R.; Szuster, F. R. (2009) Contabilidade geral: Introdução à Contabilidade Societária. 2a. ed. São Paulo: Atlas.

Vellani, C. L. (2011). Contabilidade e Responsabilidade Social. $1^{\text {a }}$ edição.

Villiers, C. \& Staden, C. (2006) Can less environmental disclosure have a legitimizing effect? Evidence from Africa. Accounting, Organization and Society, 31, pp. 763-781. doi:10.1016/j.aos.2006.03.001

Wiseman, J. (1982) An evaluation of environmental disclosures made in corporate annual reports. Accounting, Organization and Society, 7(1), pp. 553-563.

doi:10.5539/ijbm.v7n14p18 